\title{
Toplu Konutlardaki Yerleşim Kararlarının Enerji Etkin Mimarlıktaki Rolü
}

\author{
Kader Keskin $^{1 \star}$, Nihan Engin ${ }^{2}$
}

\section{Öz}

Dünya'da ve ülkemizde tüketilen enerjinin büyük bir bölümünden konutlar sorumludur. Konut alanlarında enerji gereksinimini ve kullanım talebini en alt düzeye çekmek ve enerji etkinliğini artırmak konut alanlarından kaynaklı çevresel etkileri azaltmak açısından önem taşımaktadır. Enerji etkin mimarlık yaklaşımlarında yerleşme, kütle, yapı kabuğu ve mekan gibi parametreler tasarım aşamasında ele alınarak mevcut iklim şartları en iyi şekilde değerlendirilmekte ve enerji kazanımı sağlanmaktadır.

Bu çalışmada amaç, toplu konutlarda uygulanan yerleşme kararları ile bölge ikliminin güneş ve rüzgar enerjisinden pasif olarak ne ölçüde yararlanıldığını ve/veya korunulduğunu incelemek ve değerlendirmektir. Çalışma kapsamında ılıman-nemli iklim özelliği gösteren Trabzon'da, kentin yeni ve yoğun yerleşim yerlerinden biri olan Çukurçayır çalışma alanı olarak ele alınmıştır. Çalışmada, ılıman-nemli iklimde pasif enerji kullanımı açısından uygun yükseltide yeralan toplu konutlar, mevcut alanda bulunan üç farklı yönden (kuzey, doğu ve batı aksı) seçilmiştir. Her bir yönden iki olmak üzere toplam altı toplu konutta binalar arasındaki uzaklık, yönlenme ve açık alanlardaki pasif sistem kararları analiz edilerek değerlendirilmiştir.

Çalışma sonucunda değerlendirilen toplu konutlardaki yapılar arasındaki uzaklık ile yönlenmede güneş ve rüzgardan yararlanmayı veya korunmayı sağlayacak uygun mesafe ve yönlenmenin uygulanmadığı, açık alan tasarımlarının bu anlamda oluşturulmadığı, toplu konutlarda yerleşim ile ilgili enerji etkin pasif sistem kararları alınabilecekken bu yönde bir uygulamanın gerçekleştirilmediği görülmüştür.

Anahtar kelimeler: Sürdürülebilir Mimarlık, Enerji Etkin Mimarlık, Pasif Sistemler, Ilıman-Nemli İklim Bölgesi, Yere Göre Mimarlık

\section{Role Of Energy Effıcient Architecture Of Settlement Desicion On Mass Housing}

\begin{abstract}
Housings are responsible for a large part of the energy consumed in our country and in the World. It is important to minimize energy usage and demand, and to increase energy efficiency in order to reduce the negative environmental impacts caused by residential buildings. In the design phase of energy efficient architecture, such parameters as settlement orientation, mass, building skins and space are considered,

\footnotetext{
${ }^{1}$ Ondokuzmayıs Üniversitesi, Mimarlık Fakültesi, Mimarlık Bölümü, Samsun, Türkiye

${ }^{2}$ Karadeniz Teknik Üniversitesi, Mimarlık Fakültesi, Mimarlık Bölümü, Trabzon, Türkiye nengin@ktu.edu.tr

* Corresponding author: kader.keskin@omu.edu.tr

Gönderim Tarihi: 19.02.2019

Kabul Tarihi: 29.06.2019
} 
together with the evaluation of existing climatic conditions to gain the most efficent energy usage outcomes.

The purpose of this study is to examine the energy efficiency in mass housing at the level of 'settlement' and to evaluate practices in these cases. For this purpose, the city of Trabzon, and it's dense public housing area, typical of many Turkish cities, is considered as the work area. Six housing units, each with different orientations, were examined in the area of Çukurçayır. Çukurçayır is one of the new areas of the city and is a high density settlement, in a temperate climate zone. The study aims to show through analysis how the afore mentioned characteristics are applied to this mass housing settlement, such as: the choice of building location, distance between buildings, orientation and design of open spaces and wether renewable energy systems, solar and wind were incorporated into the overall design.

As a result of the study, it has been observed that the appropriate distance and orientation to maximise the benefits of sun and wind have not been applied, and that open space designs were not created in the case study. As a result of the evaluations of the study, it has been determined that the designers of typical housing estates do not consider energy efficiency as important and therefore building orientation and locations result in a higher energy demand.

Key words: Sustainable Architecture, Energy Efficient Architecture, Passive System, Temperate-Humid Climatic Region, Architecture by Location

\section{GíRiş}

Günümüzde ekolojik dengeyi koruyan, doğal kaynakları ve doğal potansiyeli değerlendiren planlama anlayışları önem kazanmaktadır (Wang vd., 2019:1; Abbasi, 2019: 335) . Bu bağlamda kentlerde artan konut intiyacına çözüm olarak ortaya çıkmış olan, toplu konutların planlanmasında sürdürülebilir, ekolojik bir planlama yaklaşımı gözetmek gerekmektedir (Yeang 1999:56). Böylece enerji tüketiminin önemli bir kaynağı olan konut alanlarına ait enerji tüketiminin en aza indirilmesi daha sürdürülebilir çözümler yaratılmasına imkan verecektir (Hui, 2001: 630; Karaca ve Varol, 2012:129; Reena vd., 2018: 330 ).

Enerji etkin çevresel duyarlı yapıların tasarımı, yapının uygulanacağı bölgenin özelliklerine ve fiziksel çevre koşullarına göre farklılaşabilmektedir (Hong vd., 2007: 9).

Tasarım aşamasında iklim verilerini tasarıma dahil eden, yapım sürecinde çevreye duyarlı, doğal enerji kaynaklarını ve yerel malzemeyi etkin kullanan, kullanım aşamasında da kullanıcıya enerjiyi verimli kullanma bilincini yerleştirme düşüncesi enerji etkin yapı tasarım anlayışının temelini oluşturmaktadır (Zarandi 2006:4, OK 2007:214, Engin, 2012:63, Keskin 2014:15, Van Proijen, 2019: 116).

Enerji verimliliği çalışmaları gündemde yer alırken, önemli bir enerji tüketim sahası olan konut üretiminin ülkemizde hızla artması, bu alanda enerji verimliliğinin gündeme getirilmesini gerekli kılmaktadır (Hui, 2001:632; Karaca ve Varol, 2012:128). 


\section{MATERYAL ve YÖNTEM}

Enerji etkin mimarlık yaklaşımlarında yerleşme, kütle, yapı kabuğu ve mekan gibi parametreler tasarım aşamasında ele alınarak mevcut iklim şartları en iyi şekilde değerlendirilmekte ve enerji kazanımı sağlanmaktadır. Bu kazanımlar sonunda, iç ortam koşulları için tüketilen yenilenemeyen enerji tüketimi azaltılmaktadır.

Çalışmada enerji, güneş ve rüzgar enerjisi olarak ikiye ayrılmış, toplu konutların yerleşim kararlarında güneş ve rüzgar enerjisinin pasif sistem olarak mevcut kullanımı görmek amaçlanmıştır. Seçilen toplu konutların yer seçimi, yapı aralıkları, yönlenmesi ve açık alanlarının (peyzaj) tasarlanması durumu ılıman- nemli iklim bölgesinin güneş ve rüzgar etkisi özellikleri dikkate alınarak incelenmiştir.

Çalışma kapsamında Trabzon ilinde yeni ve yoğun yerleşim alanlarından biri olan Çukurçayır'da seçilen altı adet toplu konut değerlendirilmeye alınmıştır. Bir tepe üzerinde konumlanan Çukurçayır'da ılıman-nemli iklim bölgesi için uygun olan termal kuşağın orta ve üst kuşaktan yer seçimi yapılmıştır. Bu parametre doğrultusunda seçilen alanda yapılaşmanın üç farklı yönde (K-kuzey, D- doğu ve B-batı) yer aldığı görülmüştür. Bu üç farklı yönün her birinden iki adet toplu konut seçilerek rüzgar ve güneş açısından bu toplu konutların diğer parametrelere göre olan durumunu incelemek üzere alan çalışması yapılmıştır (Şekil 1).

Çalışma kapsamında seçilen toplu konutların incelenmesi için, toplu konut alanında tespit, fotoğraf çekimi ve gözlem yapılmış; belediyeden elde edilen projeler yardımıyla da toplu konutlar çalışma amacı doğrultusunda analiz edilmiştir.
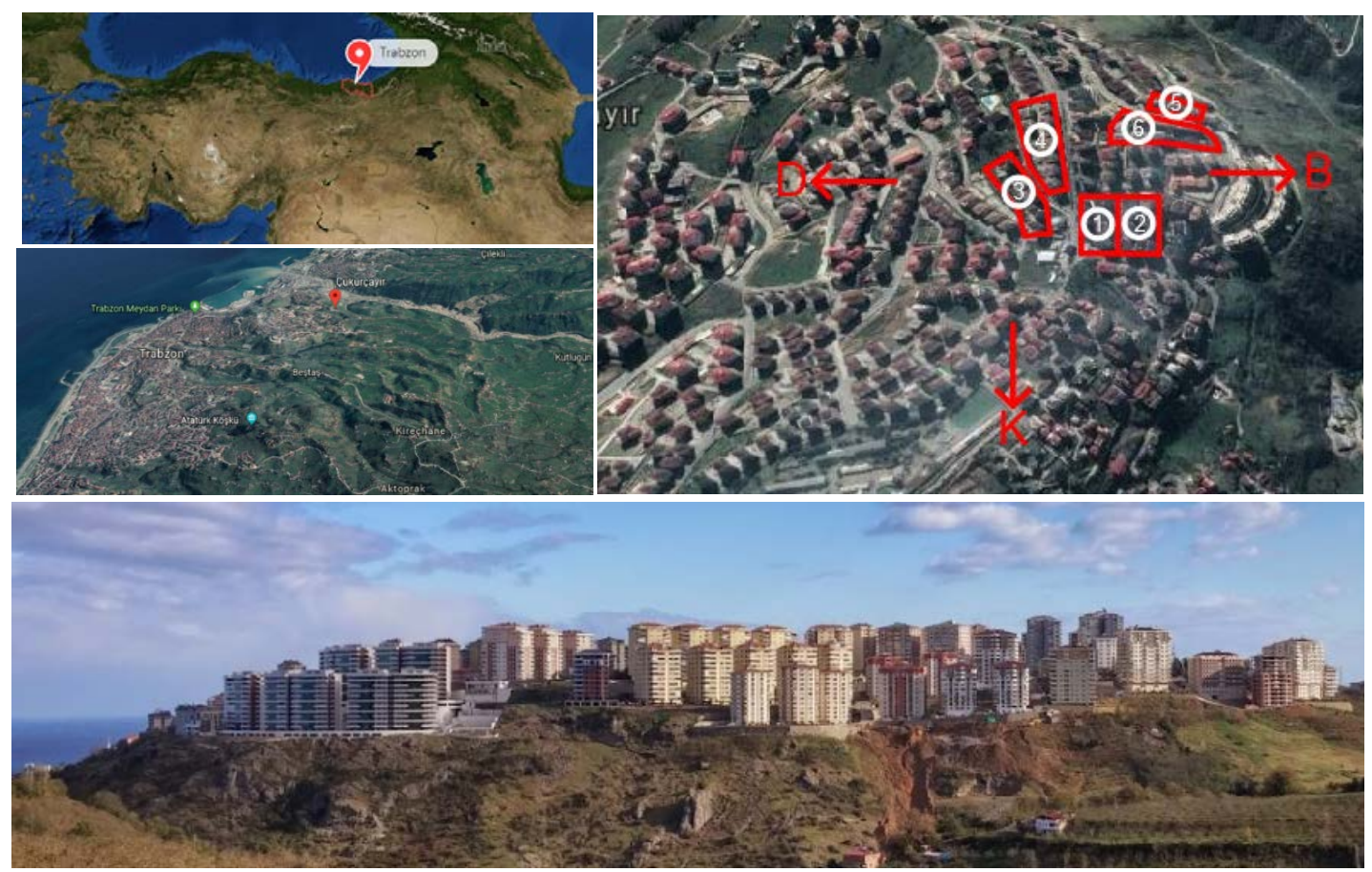

Şeki1.Trabzon- Çukurçayır'ın konumu ve görüntüsü (kaynak: Google Earth) 


\section{TOPLU KONUTLARIN YERLEŞME ÜZERINDEN ENERJI ETKIN PASIF SISTEM ANALIZi}

Çalışmadaki toplu konutlarda bölge ikliminin güneş ve rüzgar enerjisinden pasif olarak ne ölçüde yararlanıldığını ve/veya korunulduğunu öğrenmek için bir tablo oluşturulmuş, toplu konutlarda binalar arasındaki uzaklık, yönlenme ve açık alanlardaki pasif sistem kararları analiz edilerek değerlendirilmiştir. Tabloda ele alınan bina yer seçimi, yapılar arası uzaklıklar, bina yönü ve açık mekanların düzenlenmesi parametrelerini etkileyen güneş ve rüzgar faktörlerine ait bilgiler literatür taraması ile elde edilmiştir. Elde edilen bilgiler doğrultusunda oluşturulan tablo seçilen toplu konutlar üzerinde uygulanmış ve ulaşılan bulgular Tablo 2 ve Tablo 3' te gösterilmiştir. Hazırlanan tablonun uygulanması sırasında parametrelerin değerlendirilmesi amacıyla üç farklı renk kullanılmıştır. Kullanılan yeşil renk yapının belirtilen özelliği taşıdığı, mavi renk yapının belirtilen özelliği kısmen taşıdığı, kırmızı renk ise yapının belirtilen özelliği taşımadığı anlamını içermektedir. Bu şekilde yapının verilen parametre özelliğini taşıdığı, kısmen taşıdığı veya taşımadığı ifade edilmek istenmiştir. 


\subsection{Rüzgar etkisi}

Tablo 1.İncelenen toplu konutlarda rüzgarın ‘yapılar arasındaki uzaklık, yönlenme ve açık alanların tasarlanması' üzerindeki bulgusu

\section{Yapılar Arasındaki Uzaklık}

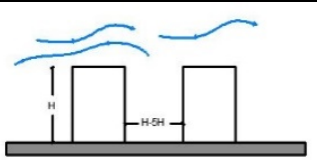

\begin{tabular}{|c|c|}
\hline \multirow{2}{*}{$\begin{array}{l}\overline{\bar{g}} \\
\frac{\vec{v}}{x} \\
\underline{x}\end{array}$} & A sitTEsi \\
\hline & B sitesi \\
\hline \multirow{2}{*}{$\begin{array}{l}\bar{n} \\
\text { 心 } \\
0\end{array}$} & C sitesi \\
\hline & D sitesi \\
\hline \multirow{2}{*}{$\begin{array}{l}\bar{y} \\
\frac{\vec{v}}{\sigma} \\
m\end{array}$} & E siTEsi \\
\hline & F SITESi \\
\hline
\end{tabular}

1. En sıcak dönemde ihtiyaç duyulan hava hareketi, engellenmeyecek şekilde yapı aralıkları korunarak ayrık yerleşme uygulanırken doğal havalandırmadan etkin yararlanmayı sağlayan binalar arasındaki mesafe hakim rüzgar doğrultusunda minimum $\mathrm{H}$ (bina boyu), maksimum $5 \mathrm{H}$ boyu ) kadar olmalıdır (Orhon, 1998'den akt: Doğan: 2012: 72)

Bina boyu: $40 \mathrm{~m}$

Binalar arası mesafe: $24 \mathrm{~m}$

Bina boyu:42,9 m

Binalar arası mesafe: $21 \mathrm{~m}$

Bina boyu: $41,8 \mathrm{~m}$

Binalar arası mesafe: $12,5 \mathrm{~m}$

Bina boyu: $37,1 \mathrm{~m}$

Binalar arası mesafe: $11 \mathrm{~m}$

Bina boyu: $37,7 \mathrm{~m}$

Binalar arası mesafe: $12 \mathrm{~m}$

Bina boyu:38 m

Binalar arası mesafe:20 m

Yönlenme

\begin{tabular}{|c|c|}
\hline \multirow{2}{*}{ 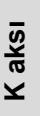 } & A siTEsi \\
\hline & B SITESi \\
\hline \multirow{2}{*}{ 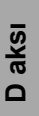 } & C SITESi \\
\hline & D SiTESi \\
\hline \multirow{2}{*}{$\begin{array}{l}\bar{n} \\
\text { 䒕 } \\
\text { m }\end{array}$} & E SiTESi \\
\hline & F siTEsi \\
\hline
\end{tabular}

2. İstenmeyen ısı kayıplarını azaltmak için nemli ve soğuk esen kuzeykuzeybatı rüzgarlarından korunmalı, yazın esen güney-güneybatı meltem rüzgarlarına geniş yüzey verilmeli, rüzgara dik ya da açılı olacak şekilde yerleştirilmelidir (Watson, 1983:101).

Yazın esen güney-güneybatı meltem rüzgarlarına ve istenmeyen rüzgar yönüne kapalı yerleşme

Yazın esen güney-güneybatı meltem rüzgarlarına kapalı istenmeyen rüzgar yönüne açık yerleşme

Yazın esen güney-güneybatı meltem rüzgarlarına ve istenmeyen rüzgar yönüne açık yerleşme

Yazın esen güney-güneybatı meltem rüzgarlarına ve istenmeyen rüzgar yönüne kapalı yerleşme Yazın esen güney-güneybatı meltem rüzgarlarına ve istenmeyen rüzgar yönüne açık yerleşme Yazın esen güney-güneybatı meltem rüzgarlarına ve istenmeyen rüzgar yönüne açık yerleşme

Açık Alanların Tasarlanması

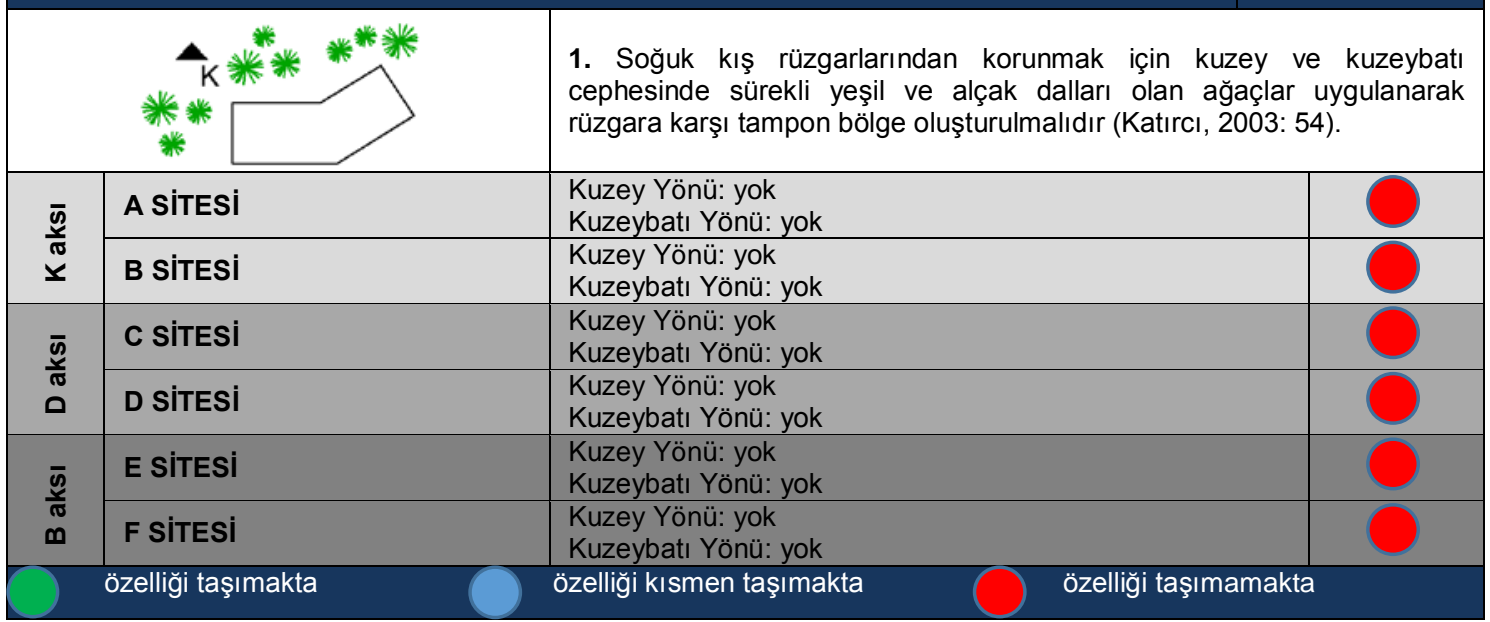




\subsection{Güneş etkisi}

Tablo 2.İncelenen toplu konutlarda güneşin 'yapılar arasındaki uzaklık, yönlenme ve açık alanların tasarlanması' üzerindeki bulgusu

Yapılar Arasındaki Uzaklık

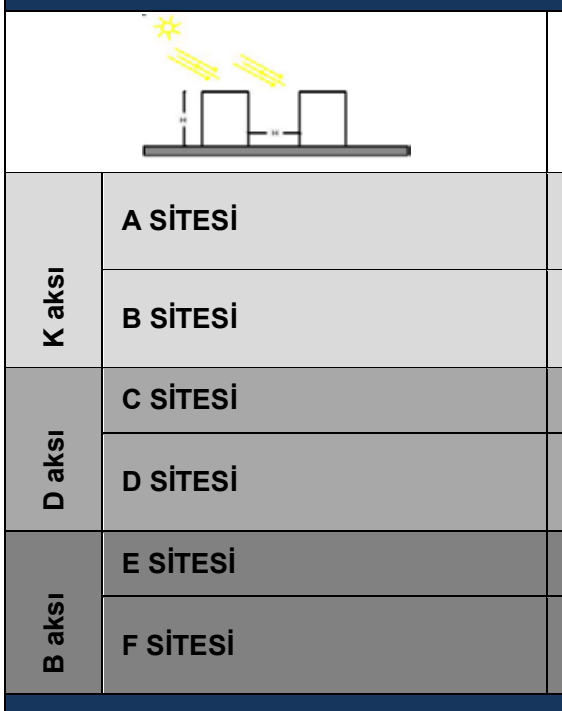

1. Gölge alanın sebep olduğu rutubeti engellemek ve gün ışığından maksimum. yararlanmak için, konutlar birbirini gölgelemeyecek şekilde ayrık yerleştirilmelidir. Binalar arasındaki mesafe binaların verdiği en uzun gölgeli alan derinliğine essit ya da bu gölge derinliğinden daha fazla olmalıdır (Özdemir, 2005: 47). Bina boyu: $40 \mathrm{~m}$

Binalar arası mesafe:8 $\mathrm{m}$ (K-G aksı) Binalar arası mesafe:24 m (D-B aksı) Bina boyu: $42,9 \mathrm{~m}$

Binalar arası mesafe: $15 \mathrm{~m}$ (K-G aksı)

Binalar arası mesafe:21 m (D-B aksı)

Bina boyu: $41,8 \mathrm{~m}$

Binalar arası mesafe: $12,5 \mathrm{~m}$ (K-G aksı)

Bina boyu: $37,1 \mathrm{~m}$

Binalar arası mesafe:11 m (K-G aksı)

Binalar arası mesafe:12m (D-B aksı)

Bina boyu: 37,7 m

Binalar arası mesafe:12 m (D-B aksı)

Bina boyu:38 m

Binalar arası mesafe:9,5 m (K-G aksı)

Binalar arası mesafe:20 m (D-B aksı)

Yönlenme

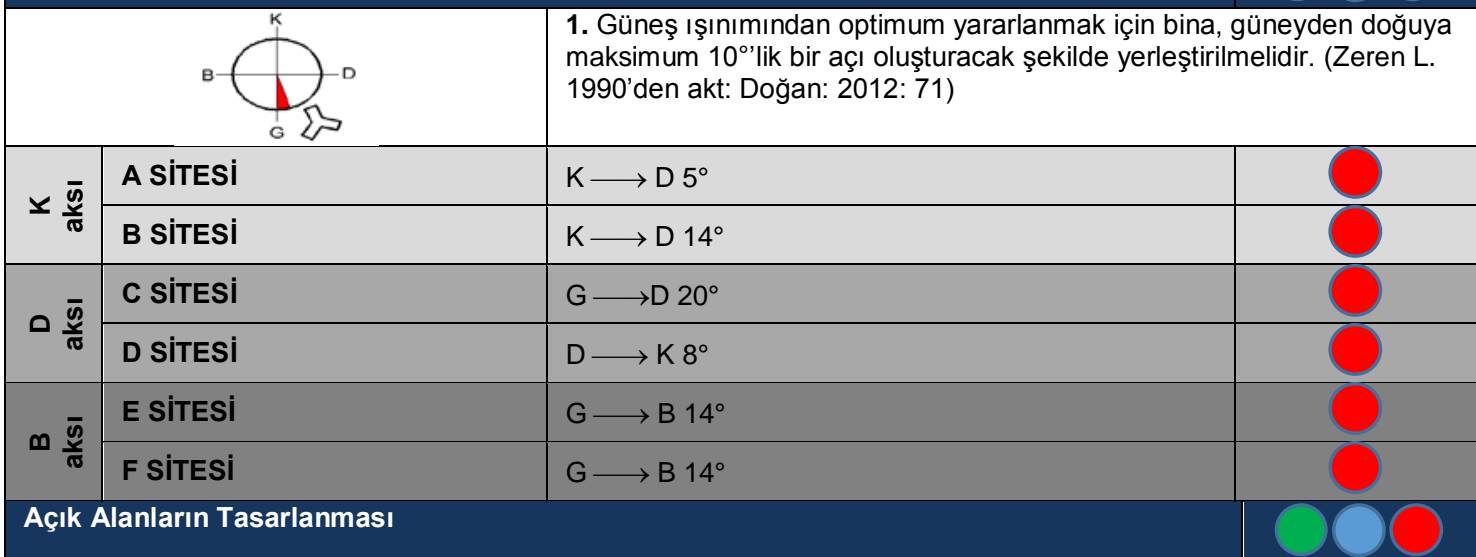

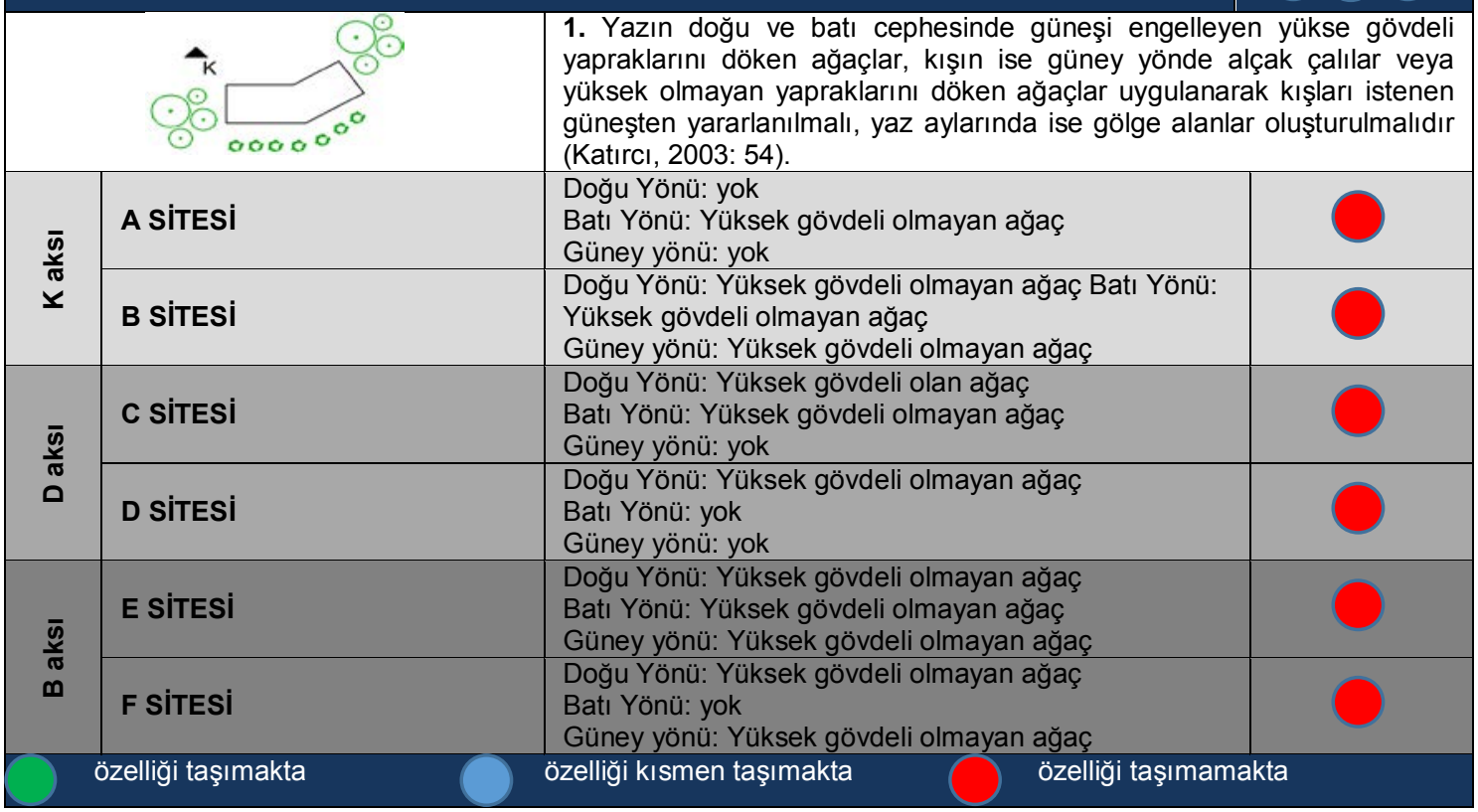


İncelenen toplu konutların tümü ılıman-nemli kuşak için uygun olan termal kuşağın üst noktalarında konumlanmakta ve yaz aylarında hissedilen sıcaklığın artmasına neden olan nemi dağıtan rüzgar etkilerinden yararlanmaktadır.

Toplu konutlarda binalar arasındaki mesafe çeşitli yönlere göre değişmekle birlikte 8-20 $\mathrm{m}$ arasındadır. Güneşten yararlanmak ve hakim rüzgardan korunmak amacı ile minimum yapı yüksekliği olarak belirlenen değer, toplu konutların hiçbirinde sağlanmamaktadır.

Güneş için uygun yönlenme doğrultusu Güney-Doğu yönü sadece bir toplu konutta sağlanmıştır.

Incelenen toplu konutlardan 4'ü yazın esen güney-güneybatı rüzgarlarına kapalı, 2'si açıktır. Ayrıca nemli ve soğuk esen, korunulması gereken kuzey-kuzeybatı rüzgarına karşı toplu konutlardan 4'ü açık 2'si ise kapalı olması nedeniyle istenilen yönlenme toplu konutlarda kısmen sağlanmıştır.

Toplu konutların hiç birinde güneş ve rüzgar korunmak veya faydalanmak amaçlı farklı yönlerde bir bitkilendirme yapılmamıştır.

\section{ANALIZLERIN DEĞERLENDIRILMESi}

Enerji tüketiminde giderek artan bir sorumluluğa sahip olan toplu konutların, yerleşme özelliklerinin güneş ve rüzgar enerjisine göre olan durumunu anlamaya yönelik yapılan çalışmadaki analizlere göre;

- Toplu konutların bina yer seçimi, ılıman-nemli iklim bölgesi yerleşimine uygun olarak termal kuşağın üst noktalarında bulunmakta ve toplu konutlar bu duruma bağıı olarak yazın artan nemi dağıtmaya yardımcı olan rüzgar etkilerinden yararlanma imkanı bulabilmektedir.

- Toplu konutlardaki binaların yapı aralıkları, arazinin değerli ve fakat yapı intiyacının fazla olması nedeniyle mevcut yönetmelikler dahilinde sık aralıklı bina yerleşimine sebep olmaktadır. Binalar arasındaki mesafeler kat yüksekliklerinden bağımsız düşünülmekte, arazi kullanımı ve taban alanları ile ilişkilendirilmemekte, güneş ve rüzgar için gerekli aralıklar göz ardı edilmektedir.

- Binaların yönlenmesi optimum bina yönü açısını belirleyen yönlerde bulunmamaktadır. Toplu konutlar konumlandırılırken yerleştikleri mevcut parselin formuna bağlı olarak yönlenmelerin yapıldığı ve buna bağlı olarak da güneş için optimum bina yönlenmesine dikkat edilmediği saptanmıştır.

- Toplu konutların çoğu yönlenme durumuna bağlı olarak yazın serinletmeyi sağlayacak olan hakim rüzgar yönüne kapalı, kışın soğuk esen kuzey-kuzeybatı rüzgarına ise açıktır. Binaların bulunduğu topoğrafyanın yönüne bağlı olarak rüzgar etkisi değişeceğinden binalar yerleştirilirken değişen bu rüzgar yönlerinin dikkate alınmadığı, parselin ve topoğrafyanın öngördüğü yerleşim yönü doğrultusunda yönlendirildiği ve buna bağlı olarak istenen/istenmeyen rüzgar yönlerinin göz ardı edildiği saptanmıştır.

- Toplu konut açık alanlarında bitkilendirmenin var olduğu fakat bu durumun yönlere göre istenen özellikteki bitki gruplarından oluşmadığı tespit edilmiştir. 
Tasarım aşamasında bazı projelerde ağaçlandırmanın öngörüldüğü ancak hızlı ve düşük maliyetli yapım getirisi düşüncesi nedeniyle uygulama aşamasında ağaçların dikilmediği görülmüştür.

Tablo 3. İncelenen toplu konutların karşılaştırılması

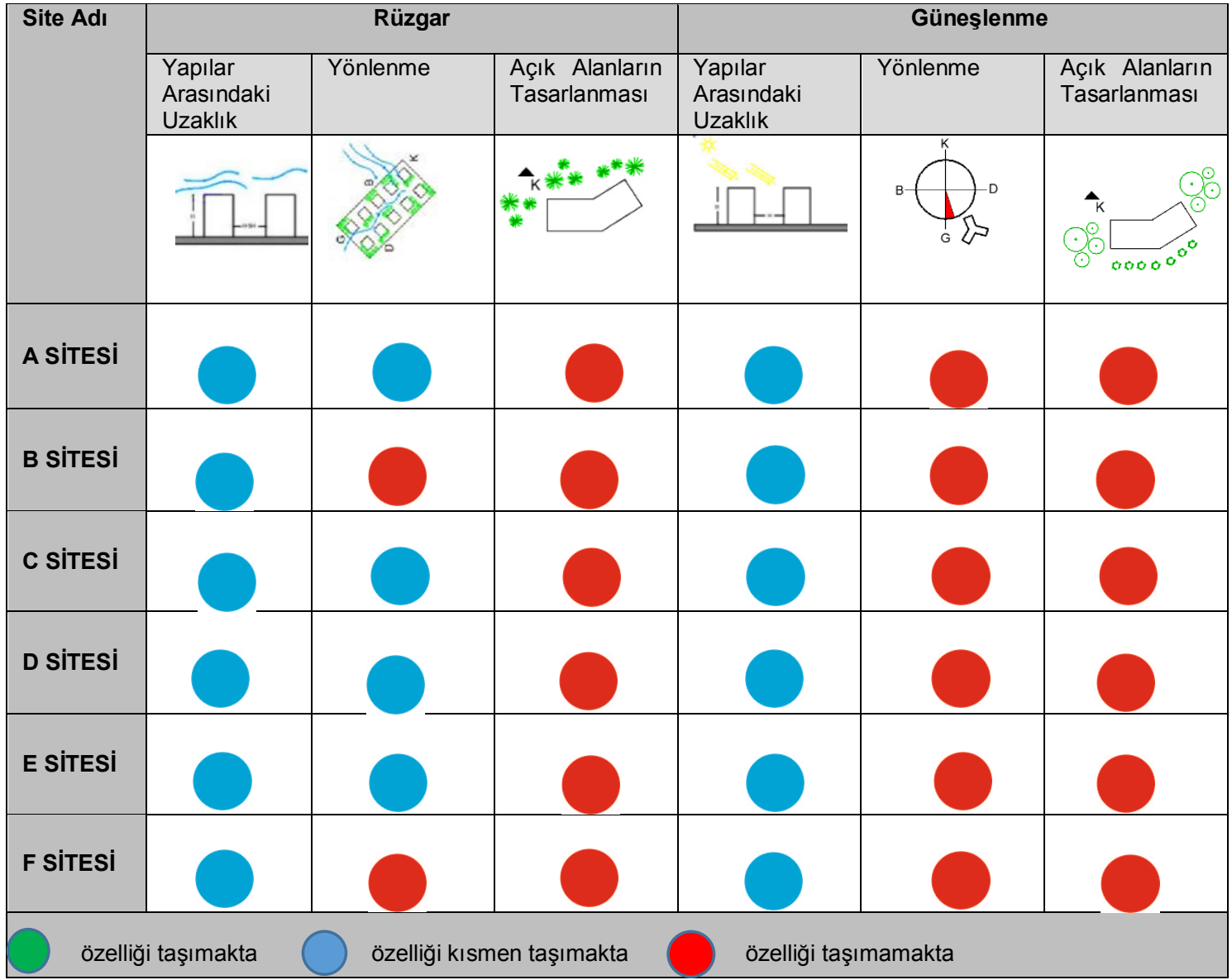

Yapılan analiz sonrasında toplu konutların karşılaştırıldığı tablo incelendiğinde, tablolarda hakim rengin kırmızı ve mavi olduğu, yeşil renge ait herhangi bir bulguya rastlanmadığı dikkat çekmektedir. İncelenen sitelerden her biri, rüzgara ve güneşe göre açık alanların tasarlanmasına yönelik istenilen özelliğe uygun olarak tasarlanmamış, güneşe göre de istenilen yönlenme sağlanamamıştır. Ancak incelenen sitelerden birçoğunun rüzgara ve güneşe göre yapılar arasındaki uzaklık ve yönlenmeyi kısmen de olsa sağladığı görülmektedir.

\section{SONUÇLAR}

Enerji etkin yapılar iklime duyarlı tasarım parametrelerini dikkate alan, enerjinin verimli bir şekilde kullanılmasına imkan tanıyan, çevreye ve insan sağlığına duyarlı yapılardır. Enerjinin etkin kullanılmasında önemli tasarım parametrelerinden birisi de 'yerleşme' dir. 
Yapılan bu çalışmada enerji etkinliği, 'yerleşme' üzerinden ele alınmıştır. Çalışma kapsamında yerleşme alanında bina yer seçimi, yapılar arasındaki uzaklık, yönlenme ve açık alanların tasarımında güneş ve rüzgarın kullanımı değerlendirilmiştir. Yapılan araştırma ve uygulama sonucunda, seçilen toplu konutların bina yer seçimi parametresi kapsamında ılıman-nemli iklim bölgesine uygun olarak, termal kuşağın üst noktalarına yerleştikleri tespit edilmiştir. Ancak bu durum alanın parselizasyonu gereği olarak karşımıza çıkmakta, toplu konutlar yerleşirken mevcut parselizasyonun termal kuşağın üst noktalarını yerleşime açması sonucu toplu konutlar bu bölgelere yerleşebilmiştir. Yapılar arasındaki uzaklıklara bakıldığında, güneş ışınımından ve yararı rüzgar etkilerinden yararlanabilmek için uygun boyutların bırakılmadığı görülmüştür. Yapıların yönlenme durumu incelendiğinde ise güneşten ve rüzgardan optimum yararlanmayı ve istenmeyen rüzgardan korunmayı sağlayacak bina yönlenmelerinin olmadığı anlaşılmıştır. Açık alanların tasarlanmasına bakıldığında ise istenilen zamanda güneşten ve rüzgardan yararlanma, istenmeyen zamanda ise güneş ve rüzgardan korunmayı sağlayacak herhangi bir bitkisel düzenlemeye gidilmediği tespit edilmiştir.

Sonuç olarak, çevre korunumu ve insan sağlığı için enerjinin etkin kullanımı önemli olmasına rağmen bu çalışmada da görüldüğü gibi toplu konutlar çoğu zaman tasarlandıkları bölgenin iklimsel ve topoğrafik özellikleri dikkate alınmadan tasarlanmakta ve tasarımlar enerji etkin sistemlere yönelik her hangi bir kaygı taşımadan uygulanmaktadır. Bu durumun temel nedeninin ise binaların konumlanacak olduğu parsele sığdırılabilecek konut sayısını artırma anlayışından kaynaklandığı düşünülmektedir. Mevcut yönetmeliklerin bu duruma izin vermesi ve pasif sistem parametreleri ile uyum göstermemesi çözülmesi gereken sorunların başında gelmektedir. Bu nedenle yaşanabilir ve sürdürülebilir bir çevre için ilgili kamu kurum ve kuruluşlar, mevcut yönetmelikleri sistemlere göre yeniden düzenlemeli ve enerji etkin yöntemlerin uygulamaları teşvik edilmelidir.

\section{KAYNAKLAR}

Abbasi, Ola Ghazi, International Responsibility for Environmental Pollution Crimes Resulting from Armed Conflicts in the Light of the Provisions of the Statute of the International Criminal Court, European Journal of Scientific Research, Vol. 151 No 3 January, 2019, pp. 335-347.

Doğan, Zöhre, Sürdürülebilir Konutlar İçin Bir Değerlendirme Sistemi, Yüksek Lisans Tezi, Fen Bilimler Enstitüsü, Mimar Sinan Güzel Sanatlar Üniversitesi, İstanbul 2012. ss.71,72.

Engin, Nihan, 'Enerji Etkin Tasarımda Pasif İklimlendirme: Doğal Havalandırma', Tesisat Mühendisliği, 2012, ss. 62-70.

Hong, Wen; Steller Chiang, Madelaine; Shapiro, Ruth A. and Clifford, Mark L., Building Energy Efficiency, Why Green Buildings Are Key to Asia's Future, 1. Press, Hong Kong 2007, p.9.

Hui, Sam C.M., Low Energy Building Design in High Density Urban Cities, Renewable Energy, No.24, Pergamon, Elsevier Science Ltd., 2001, s.627-640. 
Karaca, Mehmet ve Varol, Çiğdem, Konut Alanlarında Enerji Etkinliği: Toplu Konut İdaresi Başkanlığı (TOKi) Toplu Konut Projeleri Üzerine Eleştirel Bir Değerlendirme, METU JFA 2012/2 (29: 2) 127-141.

Katırcı, Uğur, Çevre ve Yaşam İçin Yapı Tasarımı: Norman Foster, Yüksek Lisans Tezi, Gazi Üniversitesi Fen Bilimleri Enstitüsü, Ankara 2003, ss.54.

Keskin, Kader, Enerji Etkin Pasif Sistem Parametrelerine Yönelik Bir Model Önerisi /llıman Nemli İklim Bölgesi Örneği, Yüksek Lisans Tezi, Fen Bilimleri Enstitüsü, Karadeniz Teknik Üniversitesi, Trabzon 2014. s.15.

Reena, Marry; Mathew Abraham and Jacob, Lillykutty, A flexible control strategy for energy and comfort aware HVAC in large Buildings, BuildingandEnvironment, 145 ,2018 pp. 330-342.

OK, Vildan, "Sağlıklı Kentler İçin Pasif İklimlendirme ve Bina Aerodinamiği", VIII. Ulusal Tesisat Mühendisliği Kongresi, İzmir 2007, 213-227.

Orhon, İmre, Toplu Konut İşletmesi, Proje Planlama-Tasarım El Kitabı, Tübitak Yayınları, Yayın No: U.9, Ankara 1988.

Özdemir, Banu Bahar, Sürdürülebilir Çevre İçin Binaların Enerji Etkin Olarak Tasarlanması,Yüksek Lisans Tezi, İstanbul Teknik Üniversitesi Fen Bilimleri Enstitüsü, İstanbul 2005. ss.47.

Van Proijen, Anne Marie, Public trust in energy suppliers' communicated motives for investing in wind power, Journal of Environmental Psychology 61, 2019, pp.115-124.

Wang, Yi; Cao, Yingxue and Meng, Xiaojing, Energy efficiency of industrial buildings, Indoor and Built Environment, 2019, 0(0) pp.1-5.

Watson, Donald and Kenneth Labs, "Climatic Building Design Energy Efficient Building Principles and Pracrise", McGraw-Hill Book Company, 1. Press, New York 1983.p.101.

Yeang, Ken, The Green Skyscraper: The Basis For Designing Sustainable Intensive Buildings, Prestel Verlag, 1. Press, Munich 1999.p.56.

Zarandi, Mahmoudi M., Natural ventilation as a solution towards sustainability in architecture, İnternational Workshop on Energy Performance and Environmental Quality of Buildings, Milos İsland, Greece 2006,pp.1-4.

Zeren, Lütfi, Fiziksel Çevre Kontrolü Ders Notları, Fiziksel Çevre Kontrolü Birimi, İstanbul Teknik Üniversitesi, İstanbul 1990.

Google Earth (2018). Trabzon. Erişim tarihi: 20 Temmuz 2018. Erişim saati: 17: 50, Erişim linki: https://maps.google.com/maps.Trabzon 